\title{
Quality as the basis of heightening production efficiency of milk in agricultural factories
}

\author{
V. Radko, \\ candidate of economic sciences \\ National University of Life and Environmental Sciences of Ukraine \\ I. Svynous, \\ doctor of economic sciences \\ Bila Tserkva National Agricultural University \\ D. Mykytiuk, \\ candidate of economic sciences \\ SRI "Ukragropromproductivity"
}

The purpose. Development of theoretical and methodical rules concerning assessment of mutual relations between producers i manufacturers of milk. Methods. Complex of scientific techniques of abstractlogic method (induction and deduction, analysis and synthesis, analogy and comparison, formalization and simulation) for development of theoretical rules on justification of organizational-economic factors heightening efficiency. Results. Algorithm is elaborated of process of implementation of integrated system of management of quality and safety of products on milk farms. It provides fulfillment of a complex of organizational-administrative methods, namely: construction of flowchart of production processes, analysis of gear of supervisory control of industrial process and product quality, development of registrationaccounting documentation which should be executed by the factory sequentially. The offered approach to assessment of effectiveness of guidance system of quality of milk manufacture provides utilization of multicriteria assessment on the basis of such indexes as quality and safety of products, characteristics of internal environment of the factory, pay-back of introduced system, etc. Its application will allow evaluating objectively operation of system concerning the certain requests to production process of products of certain quality. Conclusions. For assessment of efficiency of operation of integrated system of management of quality and safety of milk it is expedient to use system of productive and economic indexes (framework of milk manufacture on grades, profitableness, etc.) and criteria describing quality of control and organization of production (responsibility of staff for quality, effectiveness of measures on removal or minimization of negative development, etc.).

Key words: quality, milk, agricultural factories, supervisory control, intensification.

The modern level of milk production shows that the majority of agricultural enterprises do not receive a significant part of income due to the low milk quality level, which sold to milk processing enterprises.

The main reasons that affect the reduction of milk quality in agricultural enterprises are: the growth of animal diseases and the misuse of the medicine; low-quality feed and unbalanced cow's feeding; falsification of milk; violation milk storage technology; inappropriate care for dairy equipment for milking, cooling and storage of raw milk, its transportation; unsatisfactory sanitary condition of the premises.

Goal. Development of theoretical and methodological principles for the assessment of the relationship between milk producers and processors.

Methods. The totality of scientific elements of abstract and logical method (induction and deduction, analysis and synthesis, analogy and comparison, formalization and simulation) to develop the theoretical provisions on the substantiation of organizational and economic factors of efficiency increase.

Research results. Taking into account the results of research it is a need to to develop a complex program of milk quality management in agricultural enterprises, which provides such system of measures.

Animal breeding and veterinary (the use of scientific and progressive achievements that will provide milk quality improvement, balanced nutrition and rational using of feed additives, form of herds with high-yielding 
cows, creation of high yield varieties of feed crops with high nutritional content substances, transition to innovative methods of animals keeping, rational reproduction herds, mass prophylaxis veterinary measures).

Organizational and economic (rational organization of production processes, improving the material and technical base, formation of milk quality control, development of standards and domestic standards that determine price, demand and a proposal for milk).

Social (preparation and improvement qualifications of personnel, regular assessment and control over the quality of labor and milk, material and moral stimulation of employees for improving production figures, the creation of social and living conditions).

Research suggest that the existing system of the management of agricultural enterprises is aimed at preventing lowering quality below a certain level, i.e. measures are directed exclusively to control, not to improve the economy and improve the quality level. Obviously, elimination of measures to improve the quality of milk necessarily leads to higher production costs of products. At the same time, the setup of effective management quality system for enterprises in the long term will provide a significant economy and offset losses from lost profits [2].

Among the organizational and economic measures it is expedient to distinguish pricing strategy taking into account the goals set. Relying the price of milk sold, the farm should take into account changes in production costs, expected price level on purchased means of production, taking into account the level of inflation, the change in prices in competition environment and other factors [4]. Among the factors influencing the prices level, agricultural enterprises take into account production costs, demand (consumer), offer (competitors), redeemers (participants) of sales channels, quality of production, a system of state support.

We have developed an algorithm for the process of integrated management system of quality and safety of products at the dairy farms, which provides for execution aggregate of organizational and managerial measures, namely: the construction of production processes flowchart, analysis of the mechanism of control over production process and quality of products, development of registration and accounting documentations, etc., which are consistently implemented by enterprise.

We substantiate the stages of implementation of the system quality management on the principles of HACCP in dairy cattle breeding. HACCP system (risk analysis and critical control points) in dairy cattle breeding is a combination measures to ensure the safety of milk raw materials by controlling everything dangerous points during the production process. It should be emphasized that this is an absolutely new concept for agricultural enterprises, as many elements of this systems have been used for a long time and dairy farms. However, the integral system requires careful preparation, constant attention of management, training personnel, system approach and technical re-equipment of the enterprise.

An important element of system development quality management is availability at farms laboratories to determine quality requirements for milk raw materials. Note that most agricultural companies save on their maintenance and equipment, and functions of the milk raw materials quality control transfer to laboratories of dairy processing enterprises, which does not allow conducting operational monitoring of milk production. As a result, there is decrease of safety and quality of the milk. In addition, cases of abuse of milk processing enterprises became more often (underestimation of actual grade and fat milk) [5].

Consider step-by-step development and management of the sectoral quality system HACCP in dairy cattle breeding. It is impossible to recommend it as the only one for all businesses, specialized in milk production. Production process in agricultural enterprises trimmed in different ways: differences in keeping and animal species, levels and qualities feeding, organization of the milking process, primary processing and storage of milk.

1st stage. Issue the order on the formation HACCP team and staff information about the start of the project. The group team needed to enter an economist, technologist (or zootechnician), laboratory assistant, microbiologist.

2nd stage. Development of the HACCP plan.

2.1. Description of the products of dairy cattle industry. Milk needs to be described from the its composition, physical/chemical structure, the content of microorganisms, the type of treatment (cooled pasteurization, etc.), terms and conditions storage. Normative documents, specifications, standards, according to which the production process is organized, should also be noted. 
2.2. Construction of a production block diagram of technological process (flow diagram). This diagram is used as the basis for risk analysis.

2.3. Conducting an analysis of hazards and values of critical control points. At this stage, a list of hazards should be developed which are so important that they may damage a human health and determine their place (the dangers) of possible occurrence in the production process.

2.4. Analysis of the risk that arises in the critical control points. The system involves the control of the state of health of the cows and the staff. At this stage, the HACCP group should reveal important dangerous factors.

2.5. Justification of the critical control points CCT in the production process. Critical control points are determined by analyzing separately for each dangerous factor taken into account, and considering consistently all operations, preseen by the block diagram of the production process.

2.6. Creation of a monitoring system for each critical check point. Monitoring is a system of constant observation or measurement, which enables the guess what the critical points are under control, and make accurate registration records for future audits.

Frequency of monitoring procedures is to ensure the absence of unacceptable risk.

All registered data and documents are linked with monitoring of critical control points, must be signed by performers and presented in the HACCP work sheets.

2.7. Developing a corrective action plan. Corrective actions foresee, in case of noticed deviations, that is, exceeding the critical limit.

2.8. Documentation development. Documentation shall contain: procedures describing the HACCP system; data used for the analysis of hazardous factors; reports of work group; procedures and monitoring data; list of detected critical controls points; data of monitoring by dates, certified signatures of the personnel conducting the monitoring ring; data on deviations and corrective actions; acts of auditing.

The HACCP program documentation has to consider: the policy in the field of product safety, contain a creation order and the composition of the HACCP group; product information; production information; HACCP group reports with the justification of the choice potentially dangerous factors, results of analysis risk and selection of critical control points and defining critical boundaries; work sheets HACCP; monitoring procedures; procedures carrying out corrective actions; internal program validation of HACCP system; list registration-accounting documentation [5].

The list of registration and accounting documents can be compiled in form approved by the management of the enterprise and contain documents reflecting the cognition of the HACCP system, in which: monitoring data; deviations and actions that hum complaints, claims, complaints and events, related to the violation of safety requirements; internal audit reports.

If there is no general enterprise procedures, a procedure should be established from the approval of publication and transfer to other persons and organizations, review, registration and coding of HACCP documents.

2.9. Audit. It is conducted with a purpose of the value of the compliance of the developed program HACCP production process and evaluation its effectiveness. The result of the verification can be a review of the HACCP program.

The internal HACCP tests have probed introduced immediately after implementation this system and then with the established periodic not less than once a year or in scheduled order when new ones are detected unrecognized hazards and risks.

The verification program should include: analysis of registered claims, complaints and events related to the violation of products safety; conformity assessment in fact executable procedure documents system HACCP; performance checking warned actions; analysis of the monitoring results of the control points and actions taken, correcting; evaluation of HACCP system efficiency and making recommendations on its improvement; actualization of documents. The program Verification is developed by the HACCP team, and a report on verification is approved by the head of the organization [6].

An important element of quality management system development is the presence at farms laboratories to determine qualitative requirements to milk raw materials. Note that the majority agricultural enterprises economy money on the maintenance and equipment, and functions for determining the quality of milk-raw materials are transferred to laboratories milk-processing enterprises, which prevents them to carry out 
operative monitoring of the state of milk production. As a result, it is lowered safety and quality of the raw milk. Except, cases of abuse from dairy processing enterprises became more frequent (understatement the actual grade and fat content of milk).

An example of effective Milk quality management is the activity of the AE named after Volovikova Ltd of Rivne region, which in 2010 received ISO 9001 international quality certificate. Implementation of the quality certification system milk at the AE named after Volovikova Ltd contributed Ukraine's membership in the WTO, which is considerably expanding the opportunity to sell agricultural products, in particular dairy products, provided high quality milk through essential modernization of the technological process. High reputation of the agricultural enterprise as a stable supplier of high-quality milk gave the opportunity to obtain loans for the development of dairy cattle breeding from foreign creditors at interest lower from the average Ukrainian. So, December 1, 2011 on the farm there was a discovery of one the largest dairy complex in Ukraine sat down with a modern milking hall with an area of 7 hectares. A new Carusel milking hall AutoRotor Magnum 40 for 36 milking places produced by the company GEA Farm Technology (Germany), installed before a saloon of the type "Christmas tree" $2 \times 4$, is intended for milking cows in the maternity ward. A new cow house was built on the complex and was reconstructed 2 for 600 heads in everyone, equipped with modern ventilation equipment and equipment for drinking for 600 goals from GEA Farm Technologies.

The design capacity of the complex is 35 tons of milk per day. In the future, it is expected to increase the head from 1800 to 5000 cows and produce daily more than 100 tons of European quality milk.

The main attention is paid to controlling the keeping the requirements for critical control points. In the milk complex it is approved list of responsible persons and timetable of conducting of control and prophylactic measures, proved by the head of agricultural enterprise. Particular attention is paid for the certification of the laboratory equipment and its coworkers. This is explained by the fact that the employee control milk quality at the final stage of technological process of production.

At the dairy complex selective control of milking occurs no more than once every 3 days. Tired milk is checked by the main parameters in 2 stages: at the moment of arrival to cooling and at the time of overloading in special tanks. Workers of laboratory conduct the state of microflora of containers in which the milk is carried to milk processing enterprises.

Microclimate control in the rooms of enterprises carry out using modern means of control and microclimate is controlled automatically.

In accordance with the rules and regulations of certification ISO-9001 by the Veterinary Service of the agricultural enterprise is carried out biochemical detailed analysis of blood of cows every two months for the purpose of detecting disease. The visual inspection of animals by veterinarians is carried out daily. In the case of the detection the patients animals are isolated in a specially equipped room that is located outside complex [1].

Control over health of operators of machine milking is carried out by medical service complex and through a medical examination not less than once a year.

Sanitary inspection carries out by veterinarian service every day and state inspectors of the veterinary service at least once per month through a visual inspection of the territory of dairy complex and places of cows keeping.

As the practice of the AE named after Volovikova Ltd shows, the presence of ISO-9001 and compliance with its main provisions does not affect the level of purchasing prices for milk processing enterprises. We believe that to provide thepopulation with high quality milk in the supply contract should be a system of stimulation of agricultural producers for availability the corresponding ISO-9001 quality certificate as well as measures for mutual inspection of quality of raw materials and ready products.

\section{Conclusions.}

To evaluate the effectiveness of integrated management system of quality and safety operation it is expedient to use the system of economic indicators (milk production structure by grades, profitability etc.) and the criteria that characterize the quality management and organization of the production process (responsibility of the personnel for quality, efficiency measures to eliminate or minimize the negative manifestation, etc.). 
Proposed approach to evaluation efficiency of the milk quality management system involves use of multicriteria assessment based on such indicators, both quality and safety of products, characterization of the internal environment of the enterprises, payback of the introduced system etc. Its application will make it possible objectively assess the functioning of the system concerning the fulfillment of certain requirements for the production process of the corresponding quality.

Consequently, milk quality is one of the most important the underlying causes of intensification, a subordinate factor raising the efficiency of milk production and the competitiveness of milk products of dairy farming.

\section{Bibliography}

1. Braginets S.M. Reserves for improving energy consumption in dairy cattle /S.M.Braginets//Economy of Ukraine. - 2007. — № 8. -P. 52 - 59.

2. Datsuk-Tomchuk M.B. Directions of improvement of sales activity of enterprises of dairy product subcomplex /M.B.Datsuk-Tomchuk//Bulletin of Sumy national agric. university. — 2013. — № 5 (56). - P. $121-126$.

3. Kalnevskaya G.O. About the productive longevity of cows/G.O. Kalnevskaya//Dairy and meat cattle breeding. - 2011. - № 6. - P. 6.

4. Kolesnikova S.S. Safety or quality of milk products/S.S.Kolesnikova//Milk business. -2007 . — № 5 . - P. 40-42.

5. Kuhtin M. Receiving a qualitative and safe milk/M. Kuhtin//Livestock of Ukraine. - 2007. - No. 7. P. 7 - 8.

6. Lutsenko M.M. Promising production technologies of milk production: monograph/M.M. Lutsenko, V.V. Ivanishin., V.I. Smolar - K.: Publishing Center "Akademia ", 2006. - 192 p.

7. Massakovsky V. Concept of construction of the costs management in agricultural enterprises/B Massakovsky//Accounting and audit. - 2009. - No. 6. - P. 32 - 42.

8. Savran V. Technology and technological means of increase the quality of milk/V. Savran, T. Truskova, N. Khvatova//Offer. - 2007. - No. 9. -P. 106 - 108.

9. Svinous I.V. Global and domestic experience of milk market regulation: monogr./i.V. Svinous, AS Danilenko, O.M. Varchenko and others. - Bila Tserkva: BNAU, 2012. - 236 p.

10. Standards operating in the field of production and control of dairy products//Milk processing. - 2006. No. 1. - P. 23-24. 